\title{
Clinical Implications of Lymph Node Metastasis in Colorectal Cancer: Current Status and Future Perspectives
}

\author{
Hye Jin Kim, Gyu-Seog Choi \\ Colorectal Cancer Center, Kyungpook National University Chilgok Hospital, School of Medicine, Kyungpook National University, Daegu, \\ Korea
}

Lymph node metastasis is regarded as an indubitable prognostic factor for predicting disease recurrence and survival in patients with colorectal cancer. Lymph node status based on examination of a resected specimen is a key element of the current staging system and is also a crucial factor to determine use of adjuvant chemotherapy after surgical resection. However, the current tumor-node-metastasis (TNM) staging system only incorporates the number of metastatic lymph nodes in the $\mathrm{N}$ category. Numerous attempts have been made to supplement this simplified $\mathrm{N}$ staging including lymph node ratio, distribution of metastatic lymph nodes, tumor deposits, or extracapsular invasion. In addition, several attempts have been made to identify more specific prognostic factors in resected colorectal specimens than lymph node status. In this review, we will discuss controversies in lymph node staging and factors that may influence survival beyond lymph node status.

Keywords: Lymph node metastasis; TNM staging; Lymph node ratio; Colorectal neoplasms; Survival

\section{INTRODUCTION}

Complete resection of the primary tumor and regional lymph nodes has been accepted as the most important task in the treatment of colorectal cancer. In addition, evaluation of the surgical resection specimen is considered an essential step in identifying prognostic factors for predicting disease recurrence after surgery. The American Joint Committee on Cancer (AJCC) and International Union Against Cancer (UICC) suggested the tumor-nodemetastasis (TNM) staging system, which assesses primary tumor $(\mathrm{T})$, lymph node metastasis $(\mathrm{N})$, and distant metastasis $(\mathrm{M})$ to predict disease recurrence and survival $[1,2]$.

Lymph nodes are a key element of the TNM staging system and

Received: March 18, 2019 - Accepted: June 12, 2019

Correspondence to: Gyu-Seog Choi, M.D.

Colorectal Cancer Center, Kyungpook National University Chilgok Hospital,

807 Hoguk-ro, Buk-gu, Daegu 41404, Korea

Tel: +82-53-200-2166, Fax: +82-53-200-2027

E-mail: kyuschoi@mail.knu.ac.kr

ORCID code: https://orcid.org/0000-0001-5476-4610

(C) 2019 The Korean Society of Coloproctology

This is an open-access article distributed under the terms of the Creative Commons Attribution NonCommercial License (http://creativecommons.org/licenses/by-nc/4.0) which permits unrestricted noncommercial use, distribution, and reproduction in any medium, provided the original work is properly cited. are considered a significant factor for predicting disease-free survival (DFS) and overall survival (OS) in patients with colorectal cancer without distant metastasis. Lymph node status is also a crucial factor for determining the use of adjuvant chemotherapy after surgical resection [1-3]. Although the underlying mechanism is not clear, it is suggested that tumor cells spread from the primary tumor site to the lymph nodes via lymphatic vessels and consequently, to the next distant organ. Therefore, regional lymph node metastasis is believed an essential step in tumor cell dissemination in colorectal cancer [4].

The $\mathrm{N}$ category in the TNM staging system is categorized by the number of metastatic lymph nodes as N1 (1-3 metastatic nodes) and N2 ( $\geq 4$ metastatic nodes). Several attempts have been made to supplement the prognostic ability of this simplified $\mathrm{N}$ staging, including lymph node ratio (LNR), distribution of metastatic lymph nodes (LND), tumor deposits (TDs), and extracapsular invasion (ECI) [5-8]. In addition, several attempts have been made to identify more implacable prognostic factors in resected specimens beyond lymph node status, including venous invasion (VI) [9-11]. In this review, we will discuss these attempts against the $\mathrm{N}$ category of the TNM staging system reported in recent literature. 


\section{UPDATE TO THE N CATEGORY IN THE 8TH EDITION OF THE TNM STAGING SYSTEM}

The $\mathrm{N}$ category was divided according to the number of metastatic lymph nodes into N1, which was subdivided into N1a, N1b, and N1c, and N2, which was subdivided into N2a and N2b. This classification is similar to that given in the 7th edition (Table 1) $[12,13]$. N1c was described more clearly in the 8 th edition. In the 7 th edition, N1c was considered TDs identified in the subserosa, mesentery, or nonperitonealized pericolic or perirectal tissue without any regional nodal metastasis. In the 8th edition, presence of an identifiable vessel wall or neural tissue around a TD was categorized into lymphovascular invasion or perineural invasion, respectively.

\section{MINIMUM NUMBER OF EXAMINED LYMPH NODES}

Evaluation of an abundant number of lymph nodes had been emphasized for accurate evaluation of lymph node status in colorectal cancer [1-3, 12-15]. Fielding et al. [14] suggested an adequate minimum of 12 lymph nodes because evaluation of less than 12 lymph nodes led to a high rate of false-negative rate of lymph node metastasis, i.e. under-staging. The current TNM staging system also recommended evaluation of at least 12 nodes for proper staging. In addition, evaluation of less than 12 nodes is included as a high-risk feature of stage II colorectal cancer and leads to the use of adjuvant chemotherapy after surgical resection $[16,17]$.

Several studies have suggested examination of as many lymph nodes as possible with no fixed minimal requirement because number of examined lymph nodes is positively associated with increased survival [17-19]. These findings became the basis for introduction of LNR in stage III colorectal cancer. The positive correlation between survival and number of lymph nodes might result in the staging migration and therapeutic benefit caused by removal of a high number of regional lymph nodes.

However, wide variability has been reported in the number of examined lymph nodes. Furthermore, one population-based analysis pointed out that an adequate number of lymph nodes were examined in only $37 \%$ of patients [20]. The number of examined lymph nodes has been reported to be influenced by extent of surgical resection, diligence of pathologic examination, patient-related factors such as body mass index, right or left-sided tumor location, tumor staging, and use of neoadjuvant treatment [21-23]. When the TNM staging system began considering the concept of TD, some previously considered lymph nodes were reclassified as TDs; consequently, the total number of lymph nodes decreased $[12,13]$.

Different methods of node harvesting have been reported to increase lymph node yield from specimens for pathologic evaluation. Lisovsky et al. [24] suggested a second-look protocol that involved re-evaluation of lymph nodes in the entire mesocolon if peritumoral lymph nodes are negative, even after evaluation within $5 \mathrm{~cm}$ from both sides of the tumor edge. They reported that this method improved correlation between lymph node staging and survival. Another attempt to increase the total number of examined lymph nodes involved the use of specific dyes, such as indocyanine green or methylene blue, during operation. This technique contributed to easy identification of lymph nodes from surrounding lymphoadipose tissue. However, a more convenient method with proven efficacy is warranted for routine use in daily practice.

\section{LYMPH NODE RATIO}

LNR is defined as the ratio of the number of positive nodes to the total number of harvested nodes; the strength of this indicator is the value of these 2 parameters combined. LNR has been regarded as a good predictor of survival in stage III colon cancer, and its reliability was already demonstrated in other types of solid tumors $[25,26]$. Results from recent studies have indicated that high LNR is associated with poor DFS and OS, and that the prognostic value of LNR is better than that of N staging (suggested by the AJCC/ UICC) [5, 27-29]. A systemic review of 16 studies that included a total of 33,984 patients with stage III colorectal cancer also demonstrated that LNR had superior prognostic value compared to $\mathrm{N}$

Table 1. $\mathrm{N}$ category in the TNM staging system

\begin{tabular}{|c|c|c|c|c|c|}
\hline \multicolumn{2}{|c|}{ 6th edition } & \multicolumn{2}{|c|}{ 7th edition } & \multicolumn{2}{|c|}{ 8th edition } \\
\hline \multicolumn{6}{|c|}{ N stage } \\
\hline \multicolumn{2}{|l|}{ Nx } & \multicolumn{2}{|l|}{$N x$} & \multicolumn{2}{|l|}{ Nx } \\
\hline N1 & 1-3 metastatic nodes & N1a & 1 metastatic node & N1a & 1 metastatic node \\
\hline \multirow[t]{3}{*}{ N2 } & 4 or more metastatic nodes & N1b & 2-3 metastatic nodes & N1b & 2-3 metastatic nodes \\
\hline & & N2a & 4-6 metastatic nodes & $\mathrm{N} 2 \mathrm{a}$ & 4-6 metastatic nodes \\
\hline & & $\mathrm{N} 2 \mathrm{~b}$ & 7 or more metastatic nodes & $\mathrm{N} 2 \mathrm{~b}$ & 7 or more metastatic nodes \\
\hline
\end{tabular}

TD, tumor deposit. 
staging and that the pooled hazard ratios (HRs) of LNR for DFS and OS were 3.71 (95\% confidence interval [CI], 2.56-5.38) and 2.36 (95\% CI, 2.14-2.61), respectively [5]. Interestingly, Peng et al. [27] suggested that integrated LNR and N staging had higher prognostic value for predicting survival than each individual parameter.

Some studies reported that LNR only had a significant influence on survival in patients with adequate number of examined lymph nodes $(\geq 10-12)$ [30, 31]; however, a few studies have reported that $\mathrm{N}$ staging was superior to LNR in predicting patient survival with a high number of examined lymph nodes [32]. Antithetically, some studies have reported that LNR was an independent prognostic factor for survival, regardless of the total number of examined lymph nodes [33-38]. Recent meta-analysis of 33 studies that included a total of 75,839 patients with node-positive colorectal cancer supported these findings. In this study, high LNR was significantly associated with low DFS (HR, 2.75; 95\% CI, 2.14-3.53; $\mathrm{P}<0.001)$ and OS (HR, 1.91; 95\% CI, 1.71-2.14; P $<0.001)$. In addition, LNR remained a significant prognostic factor regardless of the number of harvested LNs; $\geq 12$ and $<12$ of harvested LNs (HR, 1.97; 95\% CI, 1.71-2.26; $\mathrm{P}<0.001$ and $\mathrm{HR}$, 1.74; 95\% CI, 1.40-2.17; P $<0.001$, respectively) [33].

A standard reference value of LNR is required for universal use of LNR for predicting prognosis; however, there is no consensus on what this value should be. In previous studies, LNR was presented as a categorical variable rather than a continuous one. Although the number of categories ranged from 2 to 10, the majority of studies divided all patients into 3 or 4 categories for better correlation to survival. In addition, the intervals between cutoff values of LNR in each category, which ranged from $5 \%$ to $25 \%$, varied in each study. A previous review article suggested $10 \%$ of median LNR as a cutoff value after evaluating 16 studies; however, this cutoff requires validation [5].

\section{DISTRIBUTION OF METASTATIC LYMPH NODES}

The Japanese classification of colorectal carcinoma has suggested different lymph node staging classified by the location of metastatic lymph nodes rather than the number of metastatic lymph nodes. In this system, metastatic lymph nodes in the pericolic region, along major vessels (intermediate), and around the roots of involved major vessels (apical) were classified as N1, N2, and N3, respectively [39]. Many studies named the stages of this grading system as LND 1, LND 2, and LND 3 to avoid confusion with the TNM staging system. This method of $\mathrm{N}$ staging was included in the 4th edition of the TNM staging system, and lymph node metastasis around the roots of major vessels was classified as N3 regardless of the number of metastatic nodes. However, this version of $\mathrm{N} 3$ was deleted from the 5th edition because of the complexity of dividing lymph node zones for pathologic evaluation. However, it remains controversial whether LND provides improved prog- nostic ability in node-positive colorectal cancer.

One study analyzed the utility of LND as a tool for further subdivision of stage III patients compared to $\mathrm{N}$ staging. This study classified 164 patients with colon cancer according to the LND grading system: $41.5 \%$ negative-node, $29.3 \%$ LND 1, 18.3\% LND 2, and $11.0 \%$ LND 3. With TNM staging, $23.8 \%$ and $34.8 \%$ of patients were classified as having N1 and N2 disease, respectively. In this study, the LND grading system also showed a wider range of survival rates than TNM staging [40].

Many studies supported that proximal LND was associated with poor survival, which reinforced incorporation of LND into the TNM staging system. Furthermore, some studies analyzed the clinical implications of LND according to tumor location. One study that evaluated 187 patients with stage III right-sided colon cancer showed that both proximal LND and N2 significantly influenced poor survival; however, they reported that LND had better prognostic ability than the TNM staging system [41]. Huh et al. [42] evaluated 1,205 patients with sigmoid colon or rectal cancer. In a total of 590 patients with stage III colorectal cancer, LND was an independent prognostic factor for both OS and DFS by multivariate analysis.

Despite evidence supporting the use of LND as a classification for metastatic lymph nodes, it has not been generally applied in clinical practice compared to the TNM system because of its laborious nature and conflicting results from several retrospective studies suggesting that pathologic $\mathrm{N}$ staging was more significantly associated with survival than LND [43]. Suzuki et al. [43] also demonstrated that $\mathrm{N}$ staging was only an independent factor for predicting 5-year OS compared to LND, which was divided patients into only two groups (LND 1 vs. LND 2 and 3) in patients with node-positive colon cancer.

Although some studies have emphasized the prognostic value of LND in patients with rectal cancer, the significance remains unclear. Kobayashi et al. [44] compared the prognostic implications between LND and N staging and showed that proximal LND was significantly associated with poor survival only in colon cancer whereas $\mathrm{N}$ staging was significantly associated with poor survival in rectal cancer. In contrast, a study evaluating 1,188 patients with rectal cancer showed that 5- and 10-year survival rates were significantly lower in patients diagnosed with proximal lymph node metastases around the origin of the inferior mesenteric artery ( $40 \%$ and $21 \%$, respectively) compared to those who did not have proximal lymph node metastases [45]. Furthermore, Leibold et al. [46] showed the predictive ability of LND by assessing 121 patients with rectal cancer who received preoperative chemoradiotherapy (CRT) followed by resection. Lymph node metastases in the proximal area around the major feeding vessels resulted in significantly lower DFS; therefore, they strongly suggested that LND should be considered in rectal cancer treated by CRT. They also recommended intensified adjuvant chemotherapy in patients with rectal cancer with proximal lymph node metastases.

Several studies have evaluated the association between survival 
and apical lymph node metastases around the main feeding artery (LND 3); they showed that patients with LND 3 had significantly poorer survival rates than patients without apical node metastases. In addition, this specific subgroup of patients with LND 3 had similar survival rates as those with stage IV disease that achieved R0 resection $[42,47]$. Consequently, they suggested that lymph node metastases located around the main vessel should be categorized as systemic metastasis rather than as regional node metastasis based on the survival data and anatomic background.

Some studies evaluated the metastatic patterns of lymph nodes, which were grouped according to tumor location based on the Japanese classification of colorectal carcinoma [39]. They evaluated lymph node metastatic patterns in detail and attempted to determine adequate surgical extent based on tumor location. Park et al. [48] evaluated 419 patients who underwent curative resection for right-sided colon cancer and lymph nodes were immediately grouped after surgery. They reported that ileocolic lymph node metastases were the most common in cecal and ascending colon cancer; however, $6.1 \%$ of patients with cecal cancer had lymph node metastases along the right-branch of the middle colon artery. Conversely, middle colic lymph node metastases were the most common in patients with transverse colon cancer while $10 \%$ showed right colic node metastases. They also evaluated the value of sigmoid mesenteric lymph node metastases in $347 \mathrm{pa}-$ tients with rectal cancer and showed that $23.2 \%$ of patients had metastases to the sigmoid mesenteric lymph node with or without metastases to the superior rectal or inferior mesenteric lymph nodes [49]. Although these aberrant lymph node metastases did not influence survival in either study, the findings emphasize that removal of these nodes is required for proper staging, but not for cure.

\section{SITE SPECIFIC CONSIDERATIONS}

The treatment of lateral pelvic node (LPN) metastasis is still controversial. In Japan, prophylactic or therapeutic lateral pelvic node dissection (LPND) have been routinely recommended for advanced lower rectal cancer to reduce local and even systemic failure $[50,51]$. The recently published JCOG0212 trial evaluated 701 patients with stage II or III rectal cancer showed lower local recurrence rates when total mesorectal excision (TME) was combined with routine LPND than TME alone. However, they did not perform preoperative CRT in these rectal cancer patients [52]. On the other hand, in western countries, preoperative CRT and TME are regarded as the standard treatment in locally advanced rectal cancer $[53,54]$. It is primarily due to effective local control by preoperative CRT, higher morbidity rates of LPND without improving oncologic results, therefore implying systemic disease $[55,56]$. Recent studies suggested TME with selective LPND for suspected LPN metastasis in patients with rectal cancer who have undergone preoperative CRT $[57,58]$. However, preoperative CRT may sterilize lymph nodes in the pelvic sidewall. Therefore, the indication criteria for LPND, especially size criteria ( $\geq 5 \mathrm{~mm}$, $\geq 7 \mathrm{~mm}$, or $\geq 10 \mathrm{~mm}$ ) and the timing of imaging studies (preoperative or postoperative) are still controversial [57-60].

Recently, some collaborative studies between western and eastern countries were published for evaluating the significance of metastatic LPN on survival rates. Ogura et al. [61] analyzed 1,216 patients with $\mathrm{cT} 3 / \mathrm{T} 4$ rectal cancer including 142 patients who underwent TME with LPND and used MRI to assess LPN features. Patients having LPN with a short-axis diameter $\geq 7 \mathrm{~mm}$ had a significantly lower local recurrence rate of $5.7 \%$ with TME plus LPND compared to a local recurrence rate of $19.5 \%$ with TME alone. The mandatories of LPND in patients who are suspected to have metastatic LPNs should be further evaluated.

Paraaortic lymph node (PALN) metastasis is uncommon in colorectal cancer with a reported incidence rate of less than $2 \%$ but is categorized as M1 in the TNM staging system with poor survival outcomes $[13,62,63]$. However, the Japanese classification of colorectal carcinoma considers it a regional, stage III disease [39]. Therefore, optimal management for PALN metastasis is still not clearly defined based on these different views.

Several case series have reported favorable survival rates by performing paraaortic lymph node dissection (PALND) in selected patients [63-65]. The outcomes featured tolerable morbidity rates ranged from $7.8 \%$ to $33 \%$. Choi et al. [63] analyzed 24 patients who underwent PALND for isolated PALN metastasis and compared them with those who did not receive surgery. Five-year OS rate was $53.4 \%$ in the PALND group versus $12.0 \%$ in the non-surgery group $(P=0.045)$. In addition, the presence of two or less PALN metastases was the only prognostic factor for better survival. Therefore, they suggested that the two or less PALN metastases can be a good indication of PALND. Gagnière et al. [65] compared the oncologic outcomes of 15 patients with isolated PALN metastasis and 10 with concurrent extra-PALN metastases. By performing PALND, patients with isolated PALN metastasis showed $56 \%$ and $51 \%$ of 5 -year OS and DFS rates, respectively while those with extra-PALN metastasis showed $51 \%$ and $13 \%$, respectively. However, further study for indications of PALND is needed. Chemotherapy with or without radiation therapy has been used as a form of salvage therapy for patients with PALN metastasis [66-68]. One meta-analysis reported that the complete response rate raged from $43 \%$ to $100 \%$ and partial response rate ranged from 27 to $57 \%$. Recurrence rates were reported from $60 \%$ to $68 \%$ and median OS was from 37 to 41 months [62]. However, Min et al. [64] reported significantly worse survival rate after CRT when compared to patients who underwent PALND. There was no multi-center, randomized study for these two different approaches to treat PALN metastasis. Further study is needed to conclude these controversies.

\section{TUMOR DEPOSIT}

TD was included in the 7th edition of the TNM staging system as 
a new category, N1c [12]. TDs were described as separate tumor nodules identified in the pericolic or perirectal adipose tissue without evidence of lymph node. The concept of TD has been undergoing changes in the past several decades, especially since it was included in the TNM staging system. TD was included in the 5 th edition of the TNM staging system and was classified according to TD size: $>3 \mathrm{~mm}$, regional lymph node metastasis and $\leq 3$ $\mathrm{mm}$, extension of T staging [69]. The current concept of TD was introduced in the 7th edition of the TNM staging system [12]. In the 8 th edition, TD was defined in further detail [13]. The definition stated that in the presence of an identifiable vessel wall or neural structure, a nodule was classified as lymphovascular invasion or perineural invasion, respectively (Table 1). To help detect vessel walls, the use of special stains may be considered in addition to routine hematoxylin-eosin stains. These changes were introduced with the concept of TD in the TNM staging system because many studies suggest that TDs are associated with advanced tumor growth and decreased survival [70-73]. In addition, Ueno et al. [74] demonstrated that a high number of TDs $(\geq 5)$ was correlated with poor survival. They also suggested that TDs showed similar survival rates as node-positive disease. Therefore, the 8th edition recommended evaluation of the number of TDs, specifically $1-4$ TDs or $\geq 5$ TDs.

However, large interobserver variability has persisted in interpretation of TDs and differentiation from discontinuous tumor spread, totally replaced lymph node, and VI. Therefore, further studies are needed to increase interobserver pathologist agreement in diagnosis of TDs.

\section{EXTRACAPSULAR INVASION}

ECI has been reported as a valuable prognostic factor related to inferior survival [75-77]. This finding was based on the morphologic features of lymph nodes rather than on the number or location of metastatic lymph nodes. ECI is defined as penetration of tumor cells from the nodal capsule into the perinodal fatty tissue. Therefore, ECI might reflect the aggressiveness of tumor biology and supplement the current lymph node staging system [78]. ECI has also emerged as a predictive factor in various solid tumors [79, 80]. In a recent meta-analysis that analyzed 1,336 patients with colorectal cancer from 13 studies, ECI was strongly correlated with advanced tumor staging and differentiation and was associated with significantly worse OS (HR, 1.75; 95\% CI, 1.42-2.16; P $<0.0001)$ and DFS (HR, 2.07; 95\% CI, 1.54-23.44; P < 0.0001) [8]. However, four studies included in this meta-analysis used an alternative definition of ECI, and one study used a different definition of ECI as extension of metastatic cells through the nodal capsule into perinodal adipose tissue and/or extranodal tumor cells [81]. Universal interobserver agreement is required to evaluate ECI in colorectal cancer. During isolation of lymph node, pathologists should include adipose tissue around lymph nodes. ECI and TDs exist in the adipose tissue surrounding lymph nodes.
Therefore, analysis of this tissue is important for appropriate evaluation of these factors.

\section{OTHER PROGNOSTIC FACTORS BEYOND LYMPH NODES}

Although TNM staging is one of most important prognostic factors for survival in colorectal cancer, a few studies have demonstrated the intriguing features of stage IIIA, which involves identification of lymph node metastasis in early T staging [82-84]. Most patients with stage IIIA disease showed excellent survival even in the presence of lymph node metastases; survival was similar to that observed in stage I and better than that observed in stage II. However, although most patients showed good survival, patients with VI and undifferentiated grade showed worse survival, similar to that of stage IIIB or stage IIIC colon cancer. Therefore, there are some exceptions to the current TNM staging system. There might be additional factors more closely related to survival than lymph node status.

Numerous studies reported that the presence of VI in a resected specimen was the most reliable risk factor for hematogenous metastases in colorectal cancer [85-87]. A hypothesis suggested to explain these findings that VI in peritumoral areas might allow entrance to systemic circulation more easily than lymph node metastases $[4,88]$.

However, one of the main reasons VI has been emphasized less than lymph node status to predict survival is because of the considerable discrepancy observed in reporting rates between pathologists compared to well-established evaluation of lymph node metastasis. Therefore, many attempts have been made to increase the detection rate of VI using special stains; some studies have demonstrated the superiority of elastin stain for detecting VI compared to the standard hematoxylin-eosin stain [89-91]. However, more evidence for the clinical implications of VI detected by special stains and comparisons with lymph node status is needed.

\section{CONCLUSION}

Since lymphatic flow from a primary tumor site was first identified, numerous studies have attempted to classify metastatic lymph nodes to accurately predict survival in colorectal cancer. The TNM staging system has been generally adopted in daily practice due to the prognostic ability and simplicity of $\mathrm{N}$ staging. However, numerous attempts have been made to improve the prognostic value of metastatic lymph nodes in colorectal cancer.

High LNR is closely associated with poor survival, although some conflicting findings are noted with respect to tumor location, preoperative treatment, and total number of lymph nodes. However, a standardized reference cutoff value of LNR is still not available. Further studies are needed to select a standardized cutoff value in the future.

Proximal LND is significantly associated with poor survival, al- 
though conflicting results are also reported with respect to tumor location, preoperative treatment, and clinical impact of apical lymph node metastasis. However, proximal LND is not used extensively because of its laborious nature. In addition, there are some conflicting results about the lymph node metastasis on specific sites including paraaortic or pelvic sidewall. Further studies are also needed for evaluating clinical significance of lymph node dissections in these specific areas.

Both TD and ECI are emerging prognostic factors for evaluation of lymph node metastases. For appropriate evaluation of these factors, pathologists should include the adipose tissue around lymph nodes identified during lymph node isolation. In addition, further interobserver agreement for identifying both TD and ECI is needed for routine use of these factors.

The intriguing oncologic outcomes of stage IIIA resulted in investigation of other prognostic factors in resected specimens, and VI is one convincing factor that potentially predicts survival. However, standardized detection of VI is still needed to evaluate its influence on survival.

\section{CONFLICT OF INTEREST}

No potential conflict of interest relevant to this article was reported.

\section{ACKNOWLEDGMENTS}

This research was supported by Basic Science Research Program through the National Research Foundation of Korea (NRF) funded by the Ministry of Science, ICT and future Planning (2016R1C1B2016002).

\section{REFERENCES}

1. Nelson H, Petrelli N, Carlin A, Couture J, Fleshman J, Guillem J, et al. Guidelines 2000 for colon and rectal cancer surgery. J Natl Cancer Inst 2001;93:583-96.

2. Greene FL, Stewart AK, Norton HJ. A new TNM staging strategy for node-positive (stage III) colon cancer: an analysis of 50,042 patients. Ann Surg 2002;236:416-21; discussion 421.

3. Gunderson LL, Jessup JM, Sargent DJ, Greene FL, Stewart AK. Revised TN categorization for colon cancer based on national survival outcomes data. J Clin Oncol 2010;28:264-71.

4. Pereira ER, Jones D, Jung K, Padera TP. The lymph node microenvironment and its role in the progression of metastatic cancer. Semin Cell Dev Biol 2015;38:98-105.

5. Ceelen W, Van Nieuwenhove Y, Pattyn P. Prognostic value of the lymph node ratio in stage III colorectal cancer: a systematic review. Ann Surg Oncol 2010;17:2847-55.

6. Nagasaki T, Akiyoshi T, Fujimoto Y, Konishi T, Nagayama S, Fukunaga $Y$, et al. Prognostic impact of distribution of lymph node metastases in stage III colon cancer. World J Surg 2015;39:3008-15.
7. Jin M, Frankel WL. Lymph node metastasis in colorectal cancer. Surg Oncol Clin N Am 2018;27:401-12.

8. Veronese N, Nottegar A, Pea A, Solmi M, Stubbs B, Capelli P, et al. Prognostic impact and implications of extracapsular lymph node involvement in colorectal cancer: a systematic review with meta-analysis. Ann Oncol 2016;27:42-8.

9. Morris M, Platell C, de Boer B, McCaul K, Iacopetta B. Population-based study of prognostic factors in stage II colonic cancer. Br J Surg 2006;93:866-71.

10. Puppa G. TNM staging of colorectal carcinoma. surgical pathology of the seventh edition. Diagn Histopathol 2011;17:243-62.

11. Messenger DE, Driman DK, Kirsch R. Developments in the assessment of venous invasion in colorectal cancer: implications for future practice and patient outcome. Hum Pathol 2012;43:965-73.

12. Edge SB, Byrd DR, Compton CC, Fritz AG, Greene FL, Trotti A, editors. AJCC cancer staging manual. 7th ed. New York: Springer; 2010.

13. Jessup JM, Goldberg RM, Asare EA. AJCC cancer staging manual. 8th ed. Chicago (IL): Springer; 2017.

14. Fielding LP, Arsenault PA, Chapuis PH, Dent O, Gathright B, Hardcastle JD, et al. Clinicopathological staging for colorectal cancer: an International Documentation System (IDS) and an International Comprehensive Anatomical Terminology (ICAT). J Gastroenterol Hepatol 1991;6:325-44.

15. Jass JR, O'Brien J, Riddell RH, Snover DC; Association of Directors of Anatomic and Surgical Pathology. Recommendations for the reporting of surgically resected specimens of colorectal carcinoma: Association of Directors of Anatomic and Surgical Pathology. Am J Clin Pathol 2008;129:13-23.

16. Benson AB 3rd, Schrag D, Somerfield MR, Cohen AM, Figueredo AT, Flynn PJ, et al. American Society of Clinical Oncology recommendations on adjuvant chemotherapy for stage II colon cancer. J Clin Oncol 2004;22:3408-19.

17. Swanson RS, Compton CC, Stewart AK, Bland KI. The prognosis of T3N0 colon cancer is dependent on the number of lymph nodes examined. Ann Surg Oncol 2003;10:65-71.

18. Johnson PM, Porter GA, Ricciardi R, Baxter NN. Increasing negative lymph node count is independently associated with improved long-term survival in stage IIIB and IIIC colon cancer. J Clin Oncol 2006;24:3570-5.

19. Chang GJ, Rodriguez-Bigas MA, Skibber JM, Moyer VA. Lymph node evaluation and survival after curative resection of colon cancer: systematic review. J Natl Cancer Inst 2007;99:433-41.

20. Baxter NN, Virnig DJ, Rothenberger DA, Morris AM, Jessurun J, Virnig BA. Lymph node evaluation in colorectal cancer patients: a population-based study. J Natl Cancer Inst 2005;97:219-25.

21. Bernhoff R, Holm T, Sjövall A, Granath F, Ekbom A, Martling A. Increased lymph node harvest in patients operated on for rightsided colon cancer: a population-based study. Colorectal Dis 2012; 14:691-6.

22. Gönen M, Schrag D, Weiser MR. Nodal staging score: a tool to assess adequate staging of node-negative colon cancer. J Clin On- 
col 2009;27:6166-71.

23. Gehoff A, Basten O, Sprenger T, Conradi LC, Bismarck C, Bandorski D, et al. Optimal lymph node harvest in rectal cancer (UICC stages II and III) after preoperative 5-FU-based radiochemotherapy. Acetone compression is a new and highly efficient method. Am J Surg Pathol 2012;36:202-13.

24. Lisovsky M, Schutz SN, Drage MG, Liu X, Suriawinata AA, Srivastava A. Number of lymph nodes in primary nodal basin and a "second look" protocol as quality indicators for optimal nodal staging of colon cancer. Arch Pathol Lab Med 2017;141:125-30.

25. Xing Y, Badgwell BD, Ross MI, Gershenwald JE, Lee JE, Mansfield PF, et al. Lymph node ratio predicts disease-specific survival in melanoma patients. Cancer 2009;115:2505-13.

26. Woodward WA, Vinh-Hung V, Ueno NT, Cheng YC, Royce M, Tai $\mathrm{P}$, et al. Prognostic value of nodal ratios in node-positive breast cancer. J Clin Oncol 2006;24:2910-6.

27. Peng J, Xu Y, Guan Z, Zhu J, Wang M, Cai G, et al. Prognostic significance of the metastatic lymph node ratio in node-positive rectal cancer. Ann Surg Oncol 2008;15:3118-23.

28. Attaallah W, Gunal O, Manukyan M, Ozden G, Yegen C. Prognostic impact of the metastatic lymph node ratio on survival in rectal cancer. Ann Coloproctol 2013;29:100-5.

29. Gao P, Song YX, Wang ZN, Xu YY, Tong LL, Zhu JL, et al. Integrated ratio of metastatic to examined lymph nodes and number of metastatic lymph nodes into the AJCC staging system for colon cancer. PLoS One 2012;7:e35021.

30. Berger AC, Sigurdson ER, LeVoyer T, Hanlon A, Mayer RJ, Macdonald JS, et al. Colon cancer survival is associated with decreasing ratio of metastatic to examined lymph nodes. J Clin Oncol 2005;23:8706-12.

31. Shimomura M, Ikeda S, Takakura Y, Kawaguchi Y, Tokunaga M, Egi $\mathrm{H}$, et al. Adequate lymph node examination is essential to ensure the prognostic value of the lymph node ratio in patients with stage III colorectal cancer. Surg Today 2011;41:1370-9.

32. Jakob MO, Guller U, Ochsner A, Oertli D, Zuber M, Viehl CT. Lymph node ratio is inferior to $\mathrm{pN}$-stage in predicting outcome in colon cancer patients with high numbers of analyzed lymph nodes. BMC Surg 2018;18:81.

33. Zhang MR, Xie TH, Chi JL, Li Y, Yang L, Yu YY, et al. Prognostic role of the lymph node ratio in node positive colorectal cancer: a meta-analysis. Oncotarget 2016;7:72898-907.

34. Madbouly KM, Abbas KS, Hussein AM. Metastatic lymph node ratio in stage III rectal carcinoma is a valuable prognostic factor even with less than 12 lymph nodes retrieved: a prospective study. Am J Surg 2014;207:824-31.

35. Rosenberg R, Friederichs J, Schuster T, Gertler R, Maak M, Becker K, et al. Prognosis of patients with colorectal cancer is associated with lymph node ratio: a single-center analysis of 3,026 patients over a 25-year time period. Ann Surg 2008;248:968-78.

36. Peschaud F, Benoist S, Julié C, Beauchet A, Penna C, Rougier P, et al. The ratio of metastatic to examined lymph nodes is a powerful independent prognostic factor in rectal cancer. Ann Surg 2008;
248:1067-73.

37. Kim YS, Kim JH, Yoon SM, Choi EK, Ahn SD, Lee SW, et al. lymph node ratio as a prognostic factor in patients with stage III rectal cancer treated with total mesorectal excision followed by chemoradiotherapy. Int J Radiat Oncol Biol Phys 2009;74:796802.

38. Isik A, Peker K, Firat D, Yilmaz B, Sayar I, Idiz O, et al. Importance of metastatic lymph node ratio in non-metastatic, lymph node-invaded colon cancer: a clinical trial. Med Sci Monit 2014; 20:1369-75.

39. Watanabe T, Itabashi M, Shimada Y, Tanaka S, Ito Y, Ajioka Y, et al. Japanese Society for Cancer of the Colon and Rectum (JSCCR) guidelines 2010 for the treatment of colorectal cancer. Int J Clin Oncol 2012;17:1-29.

40. Hida J, Okuno K, Yasutomi M, Yoshifuji T, Matsuzaki T, Uchida T, et al. Number versus distribution in classifying regional lymph node metastases from colon cancer. J Am Coll Surg 2005;201:21722.

41. Kim CH, Huh JW, Kim HR, Kim YJ. Prognostic comparison between number and distribution of lymph node metastases in patients with right-sided colon cancer. Ann Surg Oncol 2014;21: 1361-8.

42. Huh JW, Kim YJ, Kim HR. Distribution of lymph node metastases is an independent predictor of survival for sigmoid colon and rectal cancer. Ann Surg 2012;255:70-8.

43. Suzuki O, Sekishita Y, Shiono T, Ono K, Fujimori M, Kondo S. Number of lymph node metastases is better predictor of prognosis than level of lymph node metastasis in patients with nodepositive colon cancer. J Am Coll Surg 2006;202:732-6.

44. Kobayashi H, Ueno H, Hashiguchi Y, Mochizuki H. Distribution of lymph node metastasis is a prognostic index in patients with stage III colon cancer. Surgery 2006;139:516-22.

45. Kanemitsu Y, Hirai T, Komori K, Kato T. Survival benefit of high ligation of the inferior mesenteric artery in sigmoid colon or rectal cancer surgery. Br J Surg 2006;93:609-15.

46. Leibold T, Shia J, Ruo L, Minsky BD, Akhurst T, Gollub MJ, et al. Prognostic implications of the distribution of lymph node metastases in rectal cancer after neoadjuvant chemoradiotherapy. J Clin Oncol 2008;26:2106-11.

47. Kim JC, Lee KH, Yu CS, Kim HC, Kim JR, Chang HM, et al. The clinicopathological significance of inferior mesenteric lymph node metastasis in colorectal cancer. Eur J Surg Oncol 2004;30:271-9.

48. Park IJ, Choi GS, Kang BM, Lim KH, Jun SH. Lymph node metastasis patterns in right-sided colon cancers: is segmental resection of these tumors oncologically safe? Ann Surg Oncol 2009;16: 1501-6.

49. Park IJ, Choi GS, Lim KH, Kang BM, Jun SH. Different patterns of lymphatic spread of sigmoid, rectosigmoid, and rectal cancers. Ann Surg Oncol 2008;15:3478-83.

50. Moriya Y, Sugihara K, Akasu T, Fujita S. Importance of extended lymphadenectomy with lateral node dissection for advanced lower rectal cancer. World J Surg 1997;21:728-32. 
51. Ueno H, Mochizuki H, Hashiguchi Y, Ishiguro M, Miyoshi M, Kajiwara Y, et al. Potential prognostic benefit of lateral pelvic node dissection for rectal cancer located below the peritoneal reflection. Ann Surg 2007;245:80-7.

52. Fujita S, Mizusawa J, Kanemitsu Y, Ito M, Kinugasa Y, Komori K, et al. Mesorectal excision with or without lateral lymph node dissection for clinical stage II/III lower rectal cancer (JCOG0212): a multicenter, randomized controlled, noninferiority trial. Ann Surg 2017;266:201-7.

53. Georgiou P, Tan E, Gouvas N, Antoniou A, Brown G, Nicholls RJ, et al. Extended lymphadenectomy versus conventional surgery for rectal cancer: a meta-analysis. Lancet Oncol 2009;10:1053-62.

54. Syk E, Torkzad MR, Blomqvist L, Ljungqvist O, Glimelius B. Radiological findings do not support lateral residual tumour as a major cause of local recurrence of rectal cancer. Br J Surg 2006;93: 113-9.

55. Watanabe T, Tsurita G, Muto T, Sawada T, Sunouchi K, Higuchi Y, et al. Extended lymphadenectomy and preoperative radiotherapy for lower rectal cancers. Surgery 2002;132:27-33.

56. Nagawa H, Muto T, Sunouchi K, Higuchi Y, Tsurita G, Watanabe $\mathrm{T}$, et al. Randomized, controlled trial of lateral node dissection vs. nerve-preserving resection in patients with rectal cancer after preoperative radiotherapy. Dis Colon Rectum 2001;44:1274-80.

57. Lim SB, Yu CS, Kim CW, Yoon YS, Park SH, Kim TW, et al. Clinical implication of additional selective lateral lymph node excision in patients with locally advanced rectal cancer who underwent preoperative chemoradiotherapy. Int J Colorectal Dis 2013;28: 1667-74.

58. Akiyoshi T, Ueno M, Matsueda K, Konishi T, Fujimoto Y, Nagayama S, et al. Selective lateral pelvic lymph node dissection in patients with advanced low rectal cancer treated with preoperative chemoradiotherapy based on pretreatment imaging. Ann Surg Oncol 2014;21:189-96.

59. Oh HK, Kang SB, Lee SM, Lee SY, Ihn MH, Kim DW, et al. Neoadjuvant chemoradiotherapy affects the indications for lateral pelvic node dissection in mid/low rectal cancer with clinically suspected lateral node involvement: a multicenter retrospective cohort study. Ann Surg Oncol 2014;21:2280-7.

60. Kim HJ, Choi GS, Park JS, Park SY, Cho SH, Lee SJ, et al. Optimal treatment strategies for clinically suspicious lateral pelvic lymph node metastasis in rectal cancer. Oncotarget 2017;8:100724-33.

61. Ogura A, Konishi T, Cunningham C, Garcia-Aguilar J, Iversen H, Toda S, et al. Neoadjuvant (Chemo)radiotherapy with total mesorectal excision only is not sufficient to prevent lateral local recurrence in enlarged nodes: results of the multicenter lateral node study of patients with low ct3/4 rectal cancer. J Clin Oncol 2019; 37:33-43.

62. Wong JS, Tan GH, Teo MC. Management of para-aortic lymph node metastasis in colorectal patients: a systemic review. Surg Oncol 2016;25:411-8.

63. Choi PW, Kim HC, Kim AY, Jung SH, Yu CS, Kim JC. Extensive lymphadenectomy in colorectal cancer with isolated para-aortic lymph node metastasis below the level of renal vessels. J Surg Oncol 2010;101:66-71.

64. Min BS, Kim NK, Sohn SK, Cho CH, Lee KY, Baik SH. Isolated paraaortic lymph-node recurrence after the curative resection of colorectal carcinoma. J Surg Oncol 2008;97:136-40.

65. Gagnière J, Dupré A, Chabaud S, Peyrat P, Meeus P, Rivoire M. Retroperitoneal nodal metastases from colorectal cancer: curable metastases with radical retroperitoneal lymphadenectomy in selected patients. Eur J Surg Oncol 2015;41:731-7.

66. Kim MS, Cho CK, Yang KM, Lee DH, Moon SM, Shin YJ. Stereotactic body radiotherapy for isolated paraaortic lymph node recurrence from colorectal cancer. World J Gastroenterol 2009;15: 6091-5.

67. Yeo SG, Kim DY, Kim TH, Jung KH, Hong YS, Kim SY, et al. Curative chemoradiotherapy for isolated retroperitoneal lymph node recurrence of colorectal cancer. Radiother Oncol 2010;97:307-11.

68. Lee J, Chang JS, Shin SJ, Lim JS, Keum KC, Kim NK, et al. Incorporation of radiotherapy in the multidisciplinary treatment of isolated retroperitoneal lymph node recurrence from colorectal cancer. Ann Surg Oncol 2015;22:1520-6.

69. Fleming ID, Cooper JS, Henson DE. AJCC cancer staging manual. 5th ed. Philadelphia (PA): Lippincott-Raven Publishers; 1997.

70. Jin M, Roth R, Rock JB, Washington MK, Lehman A, Frankel WL. The impact of tumor deposits on colonic adenocarcinoma AJCC TNM staging and outcome. Am J Surg Pathol 2015;39:109-15.

71. Nagtegaal ID, Quirke P. Colorectal tumour deposits in the mesorectum and pericolon; a critical review. Histopathology 2007;51: 141-9.

72. Tong LL, Gao P, Wang ZN, Song YX, Xu YY, Sun Z, et al. Is the seventh edition of the UICC/AJCC TNM staging system reasonable for patients with tumor deposits in colorectal cancer? Ann Surg 2012;255:208-13.

73. Ueno H, Hashiguchi Y, Shimazaki H, Shinto E, Kajiwara Y, Nakanishi $\mathrm{K}$, et al. Peritumoral deposits as an adverse prognostic indicator of colorectal cancer. Am J Surg 2014;207:70-7.

74. Ueno H, Mochizuki H, Shirouzu K, Kusumi T, Yamada K, Ikega$\mathrm{mi} \mathrm{M}$, et al. Actual status of distribution and prognostic impact of extramural discontinuous cancer spread in colorectal cancer. J Clin Oncol 2011;29:2550-6.

75. Komuta K, Okudaira S, Haraguchi M, Furui J, Kanematsu T. Identification of extracapsular invasion of the metastatic lymph nodes as a useful prognostic sign in patients with resectable colorectal cancer. Dis Colon Rectum 2001;44:1838-44.

76. Suzuki H, Fujii T, Asao T, Tsutsumi S, Wada S, Araki K, et al. Extracapsular lymph node involvement is associated with colorectal liver metastases and impact outcome after hepatectomy for colorectal metastases. World J Surg 2014;38:2079-88.

77. Ueno H, Mochizuki H, Tamakuma S. Prognostic significance of extranodal microscopic foci discontinuous with primary lesion in rectal cancer. Dis Colon Rectum 1998;41:55-61.

78. Stitzenberg KB, Meyer AA, Stern SL, Cance WG, Calvo BF, Klauber-DeMore N, et al. Extracapsular extension of the sentinel 
lymph node metastasis: a predictor of nonsentinel node tumor burden. Ann Surg 2003;237:607-12; discussion 612-3.

79. Wind J, Lagarde SM, Ten Kate FJ, Ubbink DT, Bemelman WA, van Lanschot JJ. A systematic review on the significance of extracapsular lymph node involvement in gastrointestinal malignancies. Eur J Surg Oncol 2007;33:401-8.

80. Metzger R, Drebber U, Baldus SE, Mönig SP, Hölscher AH, Bollschweiler E. Extracapsular lymph node involvement differs between squamous cell and adenocarcinoma of the esophagus. Ann Surg Oncol 2009;16:447-53.

81. Fujii T, Tabe Y, Yajima R, Yamaguchi S, Tsutsumi S, Asao T, et al. Extracapsular invasion as a risk factor for disease recurrence in colorectal cancer. World J Gastroenterol 2011;17:2003-6.

82. Park SY, Choi GS, Park JS, Kim HJ, Sakai Y, Hasegawa S, et al. Distinctive oncological features of stage IIIA colorectal cancer: analysis of prognostic factors for selective adjuvant chemotherapy. J Surg Oncol 2015;111:882-90.

83. Kim MJ, Jeong SY, Choi SJ, Ryoo SB, Park JW, Park KJ, et al. Survival paradox between stage IIB/C (T4N0) and stage IIIA (T12N1) colon cancer. Ann Surg Oncol 2015;22:505-12.

84. Chu QD, Zhou M, Medeiros K, Peddi P. Positive surgical margins contribute to the survival paradox between patients with stage IIB/C (T4N0) and stage IIIA (T1-2N1, T1N2a) colon cancer. Surgery 2016;160:1333-43.

85. Messenger DE, Driman DK, McLeod RS, Riddell RH, Kirsch R.
Current practice patterns among pathologists in the assessment of venous invasion in colorectal cancer. J Clin Pathol 2011;64:9839.

86. Gibson KM, Chan C, Chapuis PH, Dent OF, Bokey L. Mural and extramural venous invasion and prognosis in colorectal cancer. Dis Colon Rectum 2014;57:916-26.

87. Stewart CJ, Morris M, de Boer B, Iacopetta B. Identification of serosal invasion and extramural venous invasion on review of Dukes' stage B colonic carcinomas and correlation with survival. Histopathology 2007;51:372-8.

88. Valastyan S, Weinberg RA. Tumor metastasis: molecular insights and evolving paradigms. Cell 2011;147:275-92.

89. Kirsch R, Messenger DE, Riddell RH, Pollett A, Cook M, AlHaddad S, et al. Venous invasion in colorectal cancer: impact of an elastin stain on detection and interobserver agreement among gastrointestinal and nongastrointestinal pathologists. Am J Surg Pathol 2013;37:200-10.

90. Vass DG, Ainsworth R, Anderson JH, Murray D, Foulis AK. The value of an elastic tissue stain in detecting venous invasion in colorectal cancer. J Clin Pathol 2004;57:769-72.

91. Howlett CJ, Tweedie EJ, Driman DK. Use of an elastic stain to show venous invasion in colorectal carcinoma: a simple technique for detection of an important prognostic factor. J Clin Pathol 2009; 62:1021-5. 